\title{
Experimental Investigation of Low Power Microwave Microplasma Source
}

\author{
D. Czylkowski ${ }^{a *}$, B. HrycAK ${ }^{a}$, M. JAsiński ${ }^{a}$ And J. MizeraCzYK ${ }^{a, b}$ \\ ${ }^{a}$ The Szewalski Institute of Fluid-Flow Machinery, Polish Academy of Sciences, Centre for Plasma \\ and Laser Engineering, J. Fiszera 14, 80-231 Gdańsk, Poland \\ ${ }^{b}$ Gdynia Maritime University, Department of Marine Electronics, Morska 81-87, 81-225 Gdynia, Poland \\ The aim of this paper is to present a novel microwave microplasma source generated in different gases at atmo- \\ spheric pressure. The design, rule of operation and experimental investigations of the new microwave microplasma \\ source are described. The main advantage of the presented microwave microplasma source is its small size, simplic- \\ ity, and low cost of construction and operation. The microplasma has a form of a small plasma jet of dimensions \\ of a few mm, depending on the kind of gas, gas flow rate, and absorbed microwave power. Presented in this paper \\ results of experimental investigations were obtained with an atmospheric pressure argon, krypton, nitrogen, and \\ air microplasma, sustained by microwaves of standard frequency of $2.45 \mathrm{GHz}$. The absorbed microwave power was \\ up to $70 \mathrm{~W}$. The gas flow rate was from 2 to $25 \mathrm{l} / \mathrm{min}$. The miniature size, simplicity of the source and stability \\ of the microplasma allow to conclude that the presented new microwave microplasma source can find practical \\ applications in various fields.
}

DOI: 10.12693 /APhysPolA.125.1323

PACS: 52.50.Dg, 52.70.Ds, 52.70.Kz, 52.80.Pi

\section{Introduction}

These days we observe a growing interest in the atmospheric pressure microplasma sources operated with various gases like argon, nitrogen, and air. Microplasma has dimensions in the range from $\mu \mathrm{m}$ to $\mathrm{mm}$. There are many merits of the use of microplasma sources: economics, portability, easy to use, less made and operation costs, and small size. They are needed for surface modifications, gas cleaning, hydrocarbon reforming, microwelding, light sources, atomic spectroscopy and many others [1-5]. They can be also used in the biomedical applications such as sterilization of medical instruments, high-precision surgery, cells treatment and deactivation of bacteria and viruses $[6,7]$.

Among different methods of microplasma generation, microwave microplasma sources (MmPSs) are of high promising. They are simple and have long lifetime, compared to other microplasma systems. Due to this last years we designed, built and tested experimentally a small, portable and easy to use MmPS [8-10]. It had structure of a coaxial line, formed by an inner conductor, made of a brass rod with a tungsten rod top and outer conductor in the form of a brass cylinder. The MmPS was operated at standard microwave frequency of $2.45 \mathrm{GHz}$. In this paper we present a novel coaxial MmPS which is much smaller than that previously mentioned. The design, rule of operation, and experimental investigations of the new MmPS are described.

*corresponding author; e-mail: dczylkowski@imp.gda.pl

\section{Experimental setup}

The diagram of the experimental setup used in these measurements is presented in Fig. 1. Its main parts were equipped with circulator, low power microwave generator of frequency of $2.45 \mathrm{GHz}$, bi-directional coupler with dual-channel power meter, the MmPS, gas supplying and flow control system, temperature, ultraviolet (UV) radiation and electromagnetic (E-M) field meters. In the experiment the microwave power $P_{\mathrm{A}}$ absorbed by the microplasma was determined from $P_{\mathrm{I}}-P_{\mathrm{R}}$, where $P_{\mathrm{I}}$ and $P_{\mathrm{R}}$ are the incident and reflected microwave powers, respectively. The incident and reflected microwave powers $P_{\mathrm{I}}$ and $P_{\mathrm{R}}$ were measured directly using bi-directional coupler equipped with dual-channel power meter.

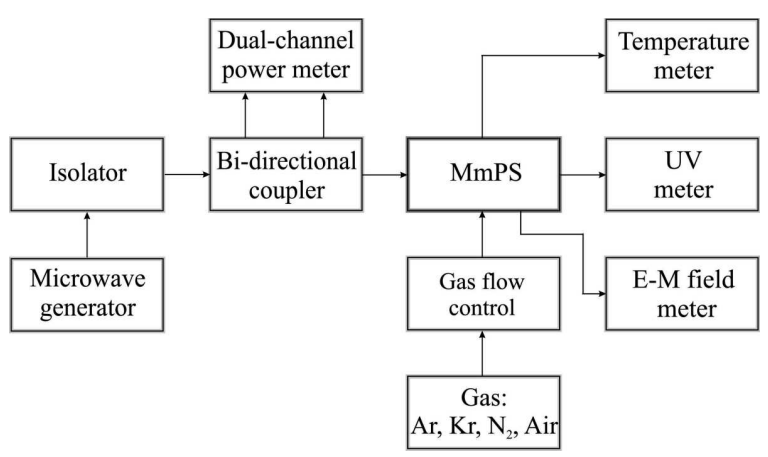

Fig. 1. The diagram of the setup for experimental investigations of MmPS.

The photo and sketch with main dimensions of our novel MmPS is presented in Fig. 2. It is based on a coaxial line formed by the inner conductor, made of a 
tungsten rod, and outer conductor in the form of a brass cylinder. The long (length $87 \mathrm{~mm}$ ) and thin coaxial line ( $5 \mathrm{~mm}$ of outer diameter) allows to reach by plasma the hardly to access cavities e.g. in stomatology applications.

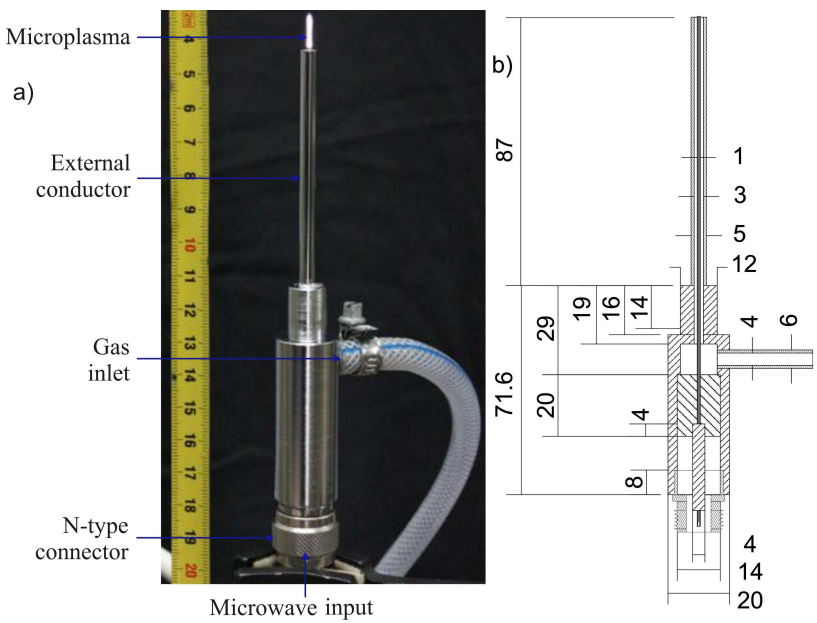

Fig. 2. Photo and sketch with dimensions of MmPS.

The operating gas is introduced through a duct between the inner and outer conductors. The MmPS is supplied from a typical low power $2.45 \mathrm{GHz}$ microwave generator through a coaxial line using an $N$-type connector. The generated microplasma has a form of a small plasma jet of dimensions of a few $\mathrm{mm}$, depending on the kind of gas, gas flow rate and absorbed microwave power.

\section{Results}

The results concerning experimental investigations of novel MmPS included: influence of operating conditions (kind of operating gas, gas flow rate, absorbed microwave power) on the size and shape of the microplasma; dependence of the reflected microwave power on the incident microwave power and on the operating gas flow rate; microplasma temperature measurements as a function of absorbed microwave power and operating gas flow rate; E-M field measurements around the MmPS and UV radiation measurements versus gas flow rate, absorbed microwave power and distance from microplasma flame.

In this paper only selected experimental results are presented. In Fig. 3 photos of the $\mathrm{Ar}, \mathrm{Kr}, \mathrm{N}_{2}$, and air microwave microplasma for various operating conditions are shown. As it can be seen the size and shape of the microplasma flame depends on the kind of the operating gas and absorbed microwave power $\left(P_{\mathrm{A}}\right)$. Also, different value of minimal absorbed microwave power is needed to generate microplasma in different gases. In the case of Ar and $\mathrm{Kr}$ a few $\mathrm{W}$ of absorbed microwave power is sufficient to initiate the discharge while in the case of $\mathrm{N}_{2}$ and air tens of $\mathrm{W}$ are needed.

The dependence of the reflected microwave power $\left(P_{\mathrm{R}}\right)$ on the incident microwave power $\left(P_{\mathrm{I}}\right)$ and on the operating gas flow rate was measured to estimate efficiency

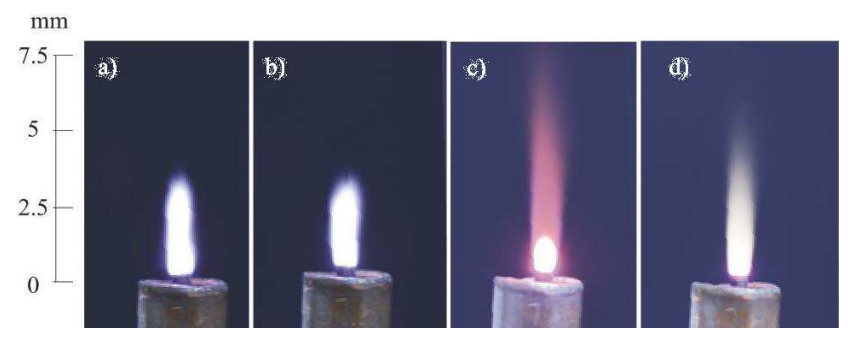

Fig. 3. Photos of the microwave microplasma generated in different gases and for various operating conditions. (a) Ar, $Q=10 \mathrm{l} / \mathrm{min}, P_{\mathrm{I}}=12 \mathrm{~W}, P_{\mathrm{R}}=10 \mathrm{~W}$, (b) Kr, $Q=10 \mathrm{l} / \mathrm{min}, P_{\mathrm{I}}=15 \mathrm{~W}, P_{\mathrm{R}}=12 \mathrm{~W}$, (c) $\mathrm{N}_{2}$, $Q=10 \mathrm{l} / \mathrm{min}, P_{\mathrm{I}}=300 \mathrm{~W}, P_{\mathrm{R}}=230 \mathrm{~W}$, (d) air, $Q=10 \mathrm{l} / \mathrm{min}, P_{\mathrm{I}}=330 \mathrm{~W}, P_{\mathrm{R}}=260 \mathrm{~W}$.

of microwave power transfer from the microwave generator to the plasma and thus to describe the stability of MmPS operation. Measurements were done for argon microplasma of gas flow rate up to $25 \mathrm{l} / \mathrm{min}$ and incident microwave power up to $125 \mathrm{~W}$. As it was observed, although the MmPS was not equipped with any impedance matching element the reflected microwave power, for choosing experimental conditions, stays at acceptable level.

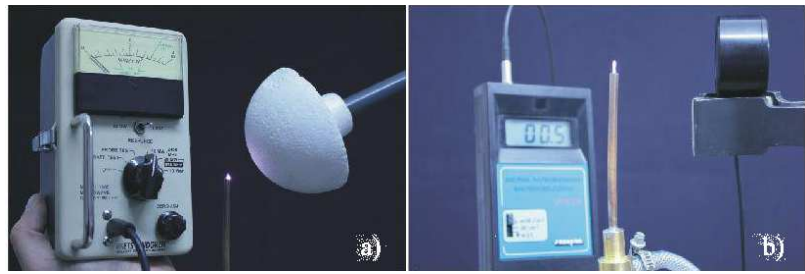

Fig. 4. Electromagnetic field intensity (a) and UV radiation (b) measurements around MmPS.

The photo showing electromagnetic field intensity measurements around the MmPS is shown in Fig. 4a. In the photo the Holaday EMF Measurement type HI-1600 meter and meter probe could be seen. Results of measurements show that all the time during the experiments the electromagnetic field intensity was never higher than $5 \mathrm{~mW} \mathrm{~cm}^{-2}$. Thus it makes our MmPS safe for personnel and instrumentation. Figure $4 \mathrm{~b}$ shows photo of UV radiation measurements around Ar microplasma flame. In the measurements the Sonopan UVB-20 meter was used. In the figure the meter detector placed parallel to the microplasma source can be seen.

Dependence of the UV radiation intensity on the absorbed microwave power is presented in Fig. 5a. The UV detector was placed perpendicularly to the MmPS. Measurement was done for two values of Ar flow rate, 5 and $10 \mathrm{l} / \mathrm{min}$. The distance of the UV detector to the Ar microplasma flame was equal to $10 \mathrm{~cm}$. From the figure the increase of the UV radiation intensity with increase of the absorbed microwave power can be seen. Dependence of the UV radiation intensity on the distance from Ar microplasma flame is shown in Fig. 5b. The Ar flow rate 


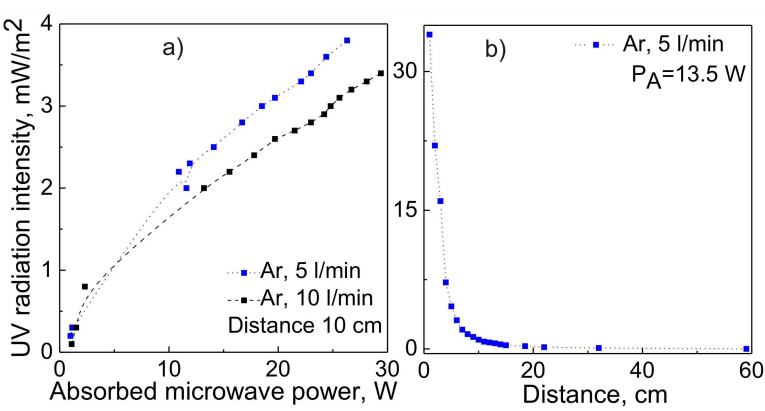

Fig. 5. Dependence of the (a) UV radiation intensity on the absorbed microwave power and (b) UV radiation intensity on the distance from MmPS.

was $5 \mathrm{l} / \mathrm{min}$ and absorbed microwave power was equal to $13.5 \mathrm{~W}$. Figure shows that UV radiation strongly depends on the distance from the MmPS and decreases with increasing the distance.

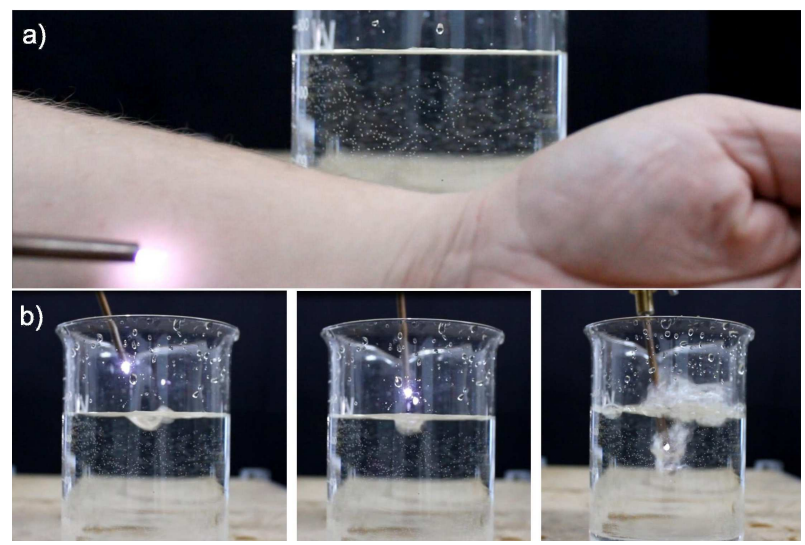

Fig. 6. Photos of the (a) Ar microplasma treatment of the human skin and (b) Ar microplasma operated in a water.

In Fig. 6a the photo showing human skin treatment using low power Ar microplasma is presented. The Ar flow rate was $10 \mathrm{l} / \mathrm{min}$ and absorbed microwave power was equal to $10 \mathrm{~W}$. Figure $6 \mathrm{~b}$ shows the photo of the possibility of Ar microplasma operating in a water. As well as the possibility of living organism treatment as possibility of operation in wet environment allows to conclude that our MmPS is a promising device for the biomedical applications. Among them, potential use in dental hygiene seems to be very interesting.

\section{Conclusions}

The results of our experimental work show that the investigated novel MmPS can be operated with a good stability and safe level of electromagnetic field intensity. It can be operated in different gases like argon, krypton, nitrogen, and air with gas flow rates of up to tens $1 /$ min. We showed that our MmPS can be used in human skin treatment and can be operated in water. The simplicity of the presented in this paper novel MmPS generator, operation stability and parameters of the microplasma allows to conclude that the presented device can find practical applications in various fields.

\section{Acknowledgments}

This research has been supported by the Szewalski Institute of Fluid-Flow Machinery, Polish Academy of Sciences under the program IMP PAN O3Z1T1.

\section{References}

[1] H. Yoshiki, Jpn. J. Appl. Phys. 45, 5618 (2006).

[2] P. Sichler, S. Büttgenbach, L. Baars-Hibbe, C. Schrader, K.H. Gericke, Chem. Eng. J. 101, 465 (2004).

[3] K. Shimizu, T. Sugiyama, M. Nishamani, M. Kanamori, in: IEEE Trans. Ind. Appl. 45,1506 (2009).

[4] H. Makoto, S. Takafumi, K. Soon-Bark, Jpn J. Appl. Phys. Part 1 45, 1801 (2006).

[5] J.A.C. Broekaert, V. Siemens, N.H. Bings, IEEE Trans. Plasma Sci. 33, 560 (2005).

[6] J. Ehlbeck, U. Schnabel, M. Polak, J. Winter, Th. von Woedtke, R. Brandenburg, T. von dem Hagen, K.D. Weltmann, J. Phys. D, Appl. Phys. 44, 013002 (2011).

[7] E. Stoffels, I.E. Kieft, R.E. Sladek, L.J.M. van den Bedem, E.M. van der Laan, M. Steinbuch, Plasma Sources Sci. Technol. 15, 169 (2006).

[8] B. Hrycak, M. Jasiński, J. Mizeraczyk, Eur. Phys. J. D 60, 609 (2010).

[9] J. Mizeraczyk, M. Dors, M. Jasiński, B. Hrycak, D. Czylkowski, Eur. Phys. J. Appl. Phys. 61, 24309 (2013).

[10] D. Czylkowski, B. Hrycak, M. Jasiński, M. Dors, J. Mizeraczyk, Surf. Coat. Technol. 234, 114 (2013). 